\title{
Paracentric inversion involving NOR of chromosome 8 in a boar : studies of synaptonemal complexes under a light microscope
}

\author{
M Świtoński \\ Academy of Agriculture, Department of Genetics and Animal Breeding, Wotyńska, 33, \\ P1-60-637 Poznań, Poland
}

(Received 13 June 1990; accepted 28 January 1991)

\begin{abstract}
Summary - In the karyotype of a boar used in artificial insemination a paracentric inversion : $\operatorname{inv}(8)(p 11, p 12)$, involving approximately $8 \%$ of the chromosome length, was identified. The inversion split the nucleolar organizer region (NOR) into 2 segments. An analysis of synaptonemal complexes carried out under a light microscope revealed that in a majority of primary spermatocytes $(87.2 \%)$ heterosynaptic "straight pairing" in pair No 8 occurred. In the remaining cells delayed pairing was found in this pair. The loop formation was not identified in any of the studied spermatocytes. In addition, no nonspecific associations between sex bivalent and autosomal bivalents were found. Consequences of the observed pairing behavior on fertility are discussed.
\end{abstract}

swine / chromosomal aberration / inversion / synaptonemal complex

Résumé - Inversion paracentrique impliquant l'organisateur nucléolaire du chromosome 8 chez un verrat; étude des complexes synaptonémiques au microscope optique. Dans le caryotype d'un verrat utilisé en insémination artificielle une inversion paracentrique, inv $(8)(p 11, p 12)$, impliquant approximativement $8 \%$ de la longueur du chromosome, a été identifiée. L'inversion partage la région de l'organisateur nucléolaire (NOR) en 2 segments. L'analyse des complexes synaptonémiques réalisée au microscope optique révèle que chez la majorité des spermatocytes primaires (87,2\%) l'hétérosynapsis de la paire $n^{\circ} 8$ intervient rapidement. Dans le reste des cellules, l'appariement pour cette paire est retardé. Aucune formation de boucle d'inversion n'a été observée chez les spermatocytes étudiés. En outre, aucune association non spécifique n'a été trouvée entre des bivalents sexuels et des bivalents autosomiques. Les conséquences pour la fertilité du mode d'appariement observé dans cette étude sont discutées.

porc / aberration chromosomique / inversion / complexe synaptonémique 


\section{INTRODUCTION}

Extensive cytogenetic studies carried out in pigs have revealed that the most frequently observed chromosomal aberrations are reciprocal translocation (Popescu et al, 1984; Long, 1988). Up till now there has been no report concerning any case of inversion in this species.

The existence of an inversion in a karyotype can be a cause of pairing disturbances at the pachytene substage of meiotic prophase I. The accepted view is that during the pairing stage loop formation is always present. Loop formation allows establishing homologous pairing between the inverted segment of one chromosome and the unchanged segment of the homologue. This can lead to crossing over within the loop and, in consequence, to the production of unbalanced gametes. On the other hand, lack of loop formation results in supression of crossing over within the inverted segment due to lack of homology and the production of only balanced gametes (Kaelbling and Fechheimer, 1985; Hale, 1986). This means that depending on pairing behavior, variable effects on fertility in carriers of inversions can be found.

This paper presents the first case of a paracentric inversion in swine, with special attention to the analysis of synaptonemal complexes under a light microscope.

\section{MATERIAL AND METHODS}

Cytogenetic studies were carried out on a boar of the Polish Landrace breed. The animal was selected from among other boars used in artificial insemination.

Mitotic chromosomes were studied by application of conventional staining and banding techniques : GTG (Seabright, 1971) and Ag-NOR (Bloom and Goodpasture, 1976). For karyotype analysis the international standard was used (Committee for the Standardized Karyotype of the Domestic Pig, 1988).

Synaptonemal complexes were obtained by the use of a spreading technique (Counce and Meyer, 1973) for light microscope. The suspension of meiotic cells was spread on drops of $0.2 \mathrm{~N}$ sucrose. The air-dried drops were fixed with $4 \%$ paraformaldehyde $(\mathrm{pH} 8.5)$, rinsed in $0.4 \%$ Photo-flo (Kodak, $\mathrm{pH} 8.5$ ) and stained with $50 \% \mathrm{AgNO}_{3}$ in a moist chamber $\left(60^{\circ} \mathrm{C}\right)$ for $2 \mathrm{~h}$.

\section{RESULTS}

\section{Mitotic chromosomes}

Chromosome analysis carried out by application of conventional and banding stainings showed in chromosome No 8 an additional chromatin fragment within the nucleolar organizer region (NOR). Silver staining revealed in this chromosome a double silver deposit. Detailed analysis of the karyotype indicated that in one chromosome from the No 8 pair a paracentric inversion had occurred. The breakage points were localized within the nucleolar organizer region and just above the region. Approximately $8 \%$ of the chromosome length was involved in the inversion. The aberration was designated as $\operatorname{inv}(8)(\mathrm{p} 11, \mathrm{p} 12)$. Partial karyotypes and a schematic drawing showing the abberation are presented in figure 1 . 


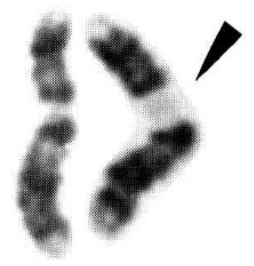

a

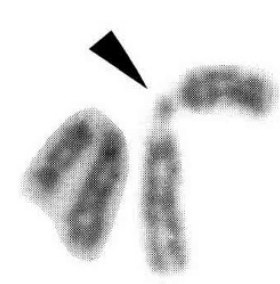

b
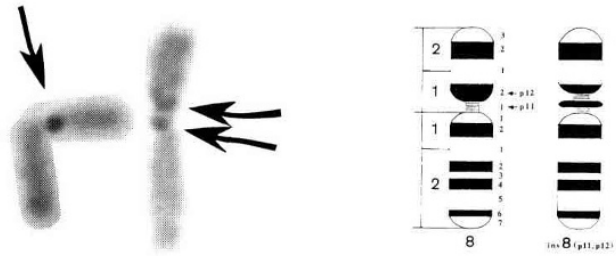

C

Fig 1. Chromosome pair No 8; a), G-band; b), conventional Giemsa staining; c), silver staining; d), schematic drawing showing G-band patterns and breakage points. Solid arrowheads indicate chromatin fragment within the nucleolar organizer region (NOR), arrows show silver deposits.

\section{Synaptonemal complexes}

Altogether 47 primary spermatocytes were analyzed under a light microscope. All cells were complete and each consisted of 18 autosomal bivalents and an XY bivalent (fig 2). The sex bivalent showed variable behavior and 4 morphological types were distinguished (table I). Types 1, 2 and 3 were classified according to the behavior of the free ends of both sex chromosomes in the following way : 1), no contact between them; 2), the free ends are associated end-to-end; and 3), the free ends are synapsed. Type 4 occurred when the axes of the sex bivalent were tangled. Most of the studied spermatocytes (57.5\%) demonstrated additional association or pairing between free ends of the $\mathrm{X}$ and $\mathrm{Y}$ chromosomes.

Table I. Occurrence of delayed pairing in chromosome pair No 8 and morphology of the sex bivalent.

Morphology of the sex bivalent

No of spermatocytes

Total With delayed pairing in pair No 8

Type 1: $\quad$ No contact between the free ends of $\mathrm{X}$ and $\mathrm{Y}$ chromosomes

15

19 of $\mathrm{X}$ and $\mathrm{Y}$ chromosomes

Type 3: $\quad$ Pairing between the free ends of $\mathrm{X}$ and $\mathrm{Y}$ chromosomes

Type 4: Tangled structure of the sex bivalent
4

3

8

0

5 


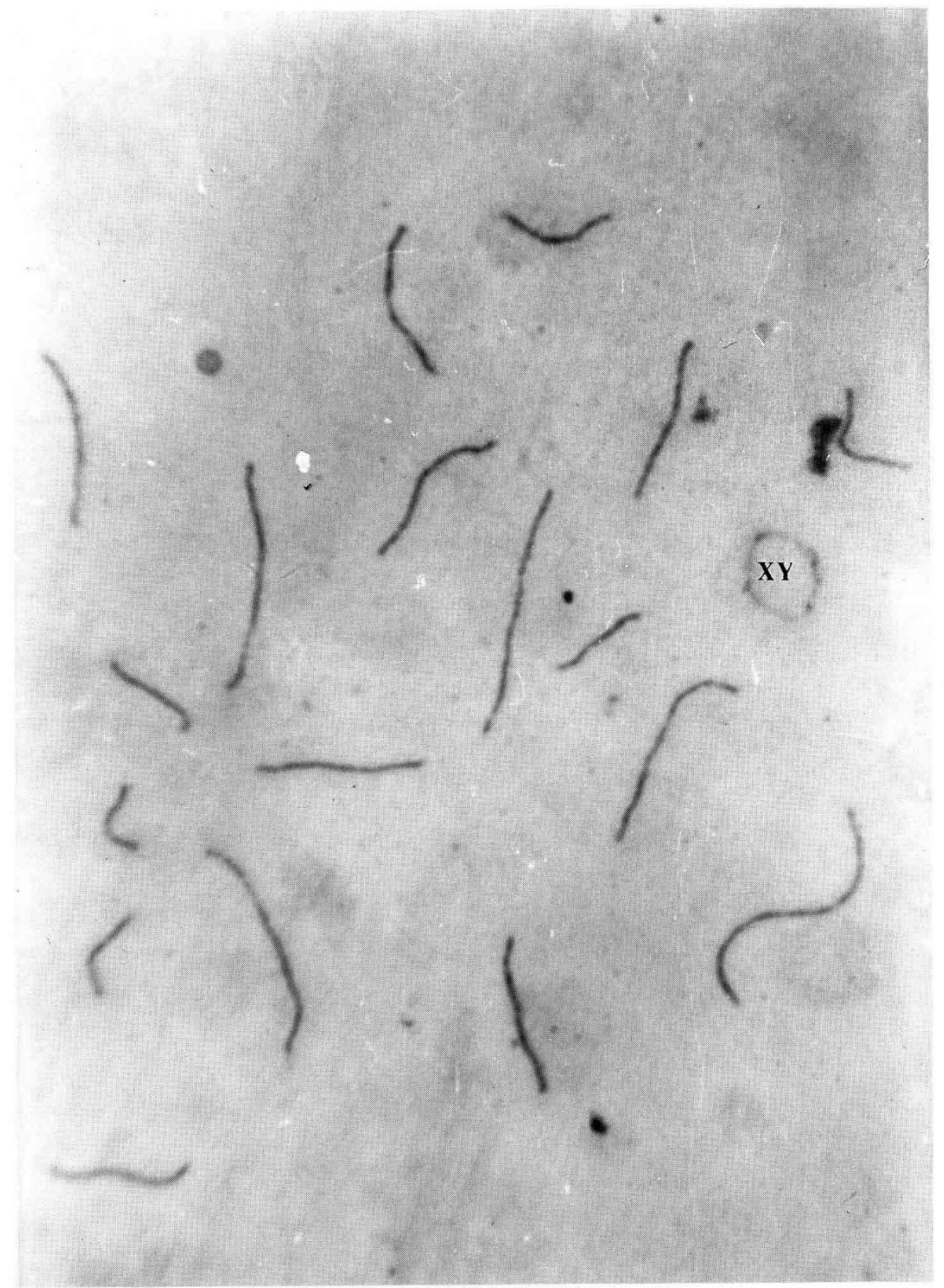

Fig 2. Primary spermatocyte with fully paired autosomal bivalents; XY bivalent is indicated. 
An analysis of autosomal bivalents showed that in the majority of spermatocytes ( 40 cells) all were fully paired. In the case of 7 spermatocytes one autosomal bivalent was partly unpaired (figs 3,4). Measurements of the length of all the autosomal bivalents within such cells showed that the bivalent with an unpaired segment had the fourth or fifth longest length. This position corresponds to the length of chromosome 8 obtained in mitotic chromosomes (Fries, 1982; Vth Committee for the Standardized Karyotype of the Domestic Pig, 1988). Delayed pairing in pair No 8 occurred in spermatocytes which had a sex bivalent of morphological type 1 or 2 (table I).

No nonspecific associations between the sex bivalent and autosomal bivalents were found.

Data concerning fertility of the inversion-carrier was not available.

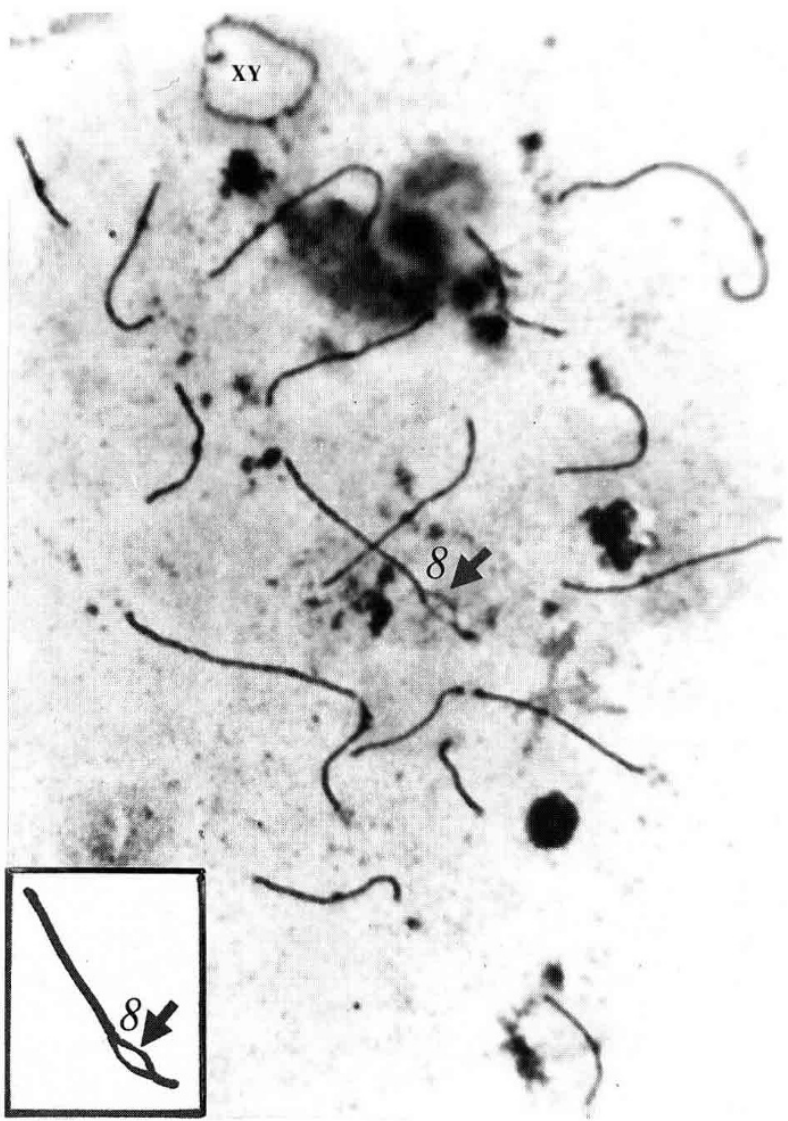

Fig 3. Primary spermatocyte with unpaired segment in the bivalent 8 ; XY bivalent is indicated. An arrow shows bivalent 8 , which is also schematically drawn in the square outlined. 

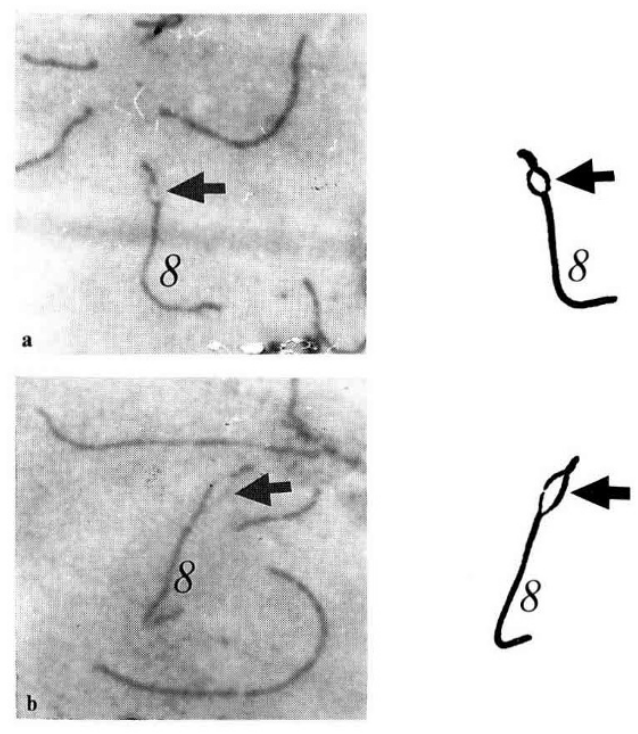

Fig 4. The bivalent 8 with unpaired segment (arrows) and schematic drawings (to the right).

\section{DISCUSSION}

The paracentric inversion described in this paper is most likely the first case of such rearrangement found in pigs. The inverted chromosomal fragment was rather small and involved $\approx 8 \%$ of the length of chromosome 8 alone. It is an open question whether the length of the inverted fragment may be responsible for this pairing behavior. In the case of inversion carriers this behavior is subdivided into 3 stages : asynapsis, loop formation and heterosynaptic "straight pairing". The classical sequence of events during late zygotene and pachytene starts with asynapsis and is followed by loop formation and, in late pachytene, the size of the loop decreases and finally heterosynaptic "straight pairing" is established. In fact, such a regular sequence of events was found to be not very common. In some cases such a sequence was observed (Davisson et al, 1981; Poorman et al, 1981; Moses et al, 1982; Guichaoua et al, 1985; Gabriel-Robez et al, 1986; Batanian and Hulten, 1987 ) but in others asynapsis was followed directly by heterosynapsis (Greenbaum and Reed, 1984 ; Kaelbling and Fechheimer, 1985; Hale, 1986 ; Hale and Greenbaum, 1988; Gabriel-Rodez et al, 1988; and the present case).

There is no clear explanation as to what factors are responsible for the pairing behavior of bivalents which are heterozygous for inversion. In a review of 6 cases of pericentric inversions in humans, de Perdigo et al (1989) indicated that loop formation occurred only in those cases where both breakage points were located within the G-light bands. In other cases, only heterosynapsis occurred. This observation was in agreement with the hypothesis formulated by Ashley (1988), 
who suggested that pairing behavior of chromosomal aberrations depended upon the breakpoint positions. In the present case the breaks occurred in the light and dark G-bands; however, it is also important to notice that a fairly small chromosomal fragment was inverted. In such a case, due to the shortness of the inverted fragment, establishment of loop formation may be impossible for physical reasons.

In the present study, behavior of the sex bivalent was used as an indicator of the sequence of pairing events during pachytene. Additional association or pairing between the free ends of the sex chromosomes has already been described in pigs (Świtoński and Gustavsson, 1986). The same phenomenon has also been observed in human spermatocytes (Chandley et al, 1984; Solari, 1988). The latter author has shown that the frequency of such a configuration increased during meiotic pairing from the late zygotene/early pachytene to later substages of pachytene. It seems reasonable to assume that due to the so-called correction phase of late pachytene (von Wettstein et al, 1984) association between free ends (type 2) is followed by pairing between free ends (type 3). The tangled structure of the sex bivalent (type 4) is generally classified as the last substage of pachytene and in Solari's (1988) classification is called a "net-like filamentous arrangement". Taking into consideration the above-mentioned remarks, it can be concluded that the observed delayed synapsis in pair No 8 occurred during the first part of pachytene (types 1 and 2). On the other hand, the low frequency of spermatocytes with delayed pairing seemed to be a result of the very short length of the inverted fragment. This probably caused a marked quickening of the process of heterosynaptic "straight pairing".

Depending on the pairing behavior, 2 main types of meiotic segregation may be expected. Loop formation establishes, by complete homologous pairing, conditions for crossing over within the loop. If this happens then dicentric or acentric chromosome fragments will arise. In such a case the fertility of the inversion carrier will be reduced due to the production of unbalanced gametes. Lack of loop formation and subsequent heterologous pairing prohibits crossing over events within the inverted fragment. This causes regular chromosome segregation and the fertility of the carrier is not affected. The latter situation probably occurred in the present case. Unfortunately, data concerning the fertility of the carrier-boar was not available.

It is known that unspecific association between the sex bivalent and autosomal configuration, particularly consisting of rearranged chromosomes (trivalents, quadrivalents, etc), can cause activation of an $\mathrm{X}$ chromosome in primary spermatocytes, which is responsible for the arrest of spermatogenesis (Lifschytz and Lindsley, 1972). In the present case, as well as in other cases of inversions described by other authors, no associations between the sex bivalent and the autosomal bivalent carrying an inversion were found.

Besides meiotic disturbances in carriers of chromosome inversions the effect of position should also be taken into consideration. The new gene neighbourhood at breakage/rejoining points can also cause activation or inhibition of gene expression.

\section{ACKNOWLEDGMENT}

I thank Mrs A Pietrzak for excellent laboratory assistance. 


\section{REFERENCES}

Ashley T (1988) G-band position effects on meiotic synapsis and crossing over. Genetics 118, 307-317

Batanian J, Hulten MA (1987) Electron microscopic investigations of synaptonemal complexes in an infertile human male carrier of a pericentric inversion inv(1)(p32, q42). Regular loop formation but defective synapsis including a possible interchromosomal effect. Hum Genet 76, 81-89

Bloom SE, Goodpasture C (1976) A improved technique for selective staining of nucleolar organizer regions in human chromosomes. Hum Genet 34, 199-206

Chandley AC, Goetz P, Hargreave TB, Joseph AM, Speed RN (1984). On the nature and extent of XY pairing at meiotic prophase in man. Cytogenet Cell Genet $38,241-247$

Committee for the Standardized Karyotype of the Domestic Pig (co-ordinator : Gustavsson I) (1988) Standard karyotype of the domestic pig. Hereditas 109, 151157

Counce SJ, Meyer GF (1973) Differentiation of the synaptonemal complex and their kinetochore in Locusta spermatocytes studied by whole mount electron microscope. Chromosoma 44, 231-253

Davisson MT, Poorman PA, Roderick TH, Moses MJ (1981) A pericentric inversion in the mouse. Cytogenet Cell Genet 30, 70-76

Fries HR (1982) Natürliche und induzierte Markerchromosomen beim Schwein und ihre Verwendung für die Genkartierung. Dissertation ETH Zürich, 7160

Gabriel-Robez O, Ratomponirina C, Rumpler Y, Le Marec B, Luciani JM, Guichaoua MR (1986) Synapsis and synaptic adjustment in an infertile human male heterozygous for a pericentric inversion in chromosome 1. Hum Genet 72, 148-152

Gabriel-Robez O, Ratomponirina C, Croquette M, Coutuerier J, Rumpler Y (1988) Synaptonemal complexes in a subfertile man with a pericentric inversion in chromosome 21. Heterosynapsis without previous homosynapsis. Cytogenet Cell Gene 48, 84-87

Greenbaum IF, Reed MJ (1984) Evidence for heterosynaptic pairing of the inverted segment in pericentric inversion heterozygotes of the deer mouse (Peromyscus maniculatus). Cytogenet Cell Genet 38, 106-111

Guichaoua MR, Delafontaine D, Taurelle R, Taillemite JL, Morazzani MR, Luciani JM (1985) Loop formation and synaptic adjustment in a human male heterozygous for two pericentric inversions. Chromosoma 93, 313-320

Hale DW (1986) Heterosynapsis and suppression of chiasmata within heterozygous pericentric inversions of the Sitka deer mouse. Chromosoma 94, 425-432

Hale DW, Greenbaum IF (1988) Synapsis of a chromosomal pair heterozygous for a pericentric inversion and the presence of a heterochromatic short arm. Cytogenet Cell Genet 48, 55-57

Kaelbling M, Fechheimer NS (1985) Synaptonemal complex analysis of a pericentric inversion in chromosome 2 of domestic fowl, Gallus domesticus. Cytogenet Cell Genet 39, 82-86

Lifschytz E, Lindsey D (1972) The role of X-inactivation during spermatogenesis. Proc Natl Acad Sci USA 69, 182-186 
Long SE (1988) Segregation patterns and fertility of domestic mammals with chromosome translocations. In : The Cytogenetics of Mammalian Autosomal Rearrangements. (Art D, ed) AR Liss Inc, New York, 383-396

Moses MJ, Poorman PA, Roderick TH, Davisson MT (1982) Synaptonemal complex analysis of mouse chromosomal rearrangement. IV. Synapsis and synaptic adjustment in two paracentric inversions. Chromosoma 84, 457-474

Perdigo A de, Gabriel-Robez O, Rumpler Y (1989) Correlation between chromosomal breakpoint positions and synaptic behaviour in human males heterozygous for a pericentric inversion. Hum Genet 83, 274-276

Poorman PA, Moses MJ, Davisson MT, Roderick TH (1981) Synaptonemal complex analysis of mouse chromosomal rearrangements. III. Cytogenetic observations on two paracentric inversions. Chromosoma 83, 419-429

Popescu CP, Bonneau M, Tixier M, Bahri I, Boscher J (1984) Reciprocal translocations in pigs. Their detection and consequences on animal performances and economic losses. $J$ Hered $75,448-452$

Seabright M (1971) A rapid banding technique for human chromosomes. Lancet 2, 971-972

Solari AJ (1988) Synaptic behaviour and recombination nodules in the human XY pair. Genetica 77, 149-158

Świtoński M, Gustavsson I (1986) The synaptonemal complex of the X-Y bivalent in pigs and cattle studied by electron microscope. 7th Eur Coll Cytogenetics of Domestic Animals, Warsaw, abstr, 40-41

Wettstein D von, Rasmussen SW, Holm PB (1984) The synaptonemal complex in genetic segregation. Ann Rev Genet 18, 331-413 